\title{
Uniportal video-assisted right S9-10 anatomical segmentectomy: how to do it
}

\author{
Sergio Bolufer ${ }^{1}$, Julio Sesma ${ }^{1}$, Carlos Gálvez ${ }^{1}$, Francisco Lirio ${ }^{1}$, Jone Del Campo ${ }^{1}$, Juan Jose Mafe ${ }^{1}$, \\ Maria Galiana ${ }^{2}$, Jorge Cerezal ${ }^{1}$ \\ ${ }^{1}$ Thoracic Surgery Department, ${ }^{2}$ Anaesthesiology Department, Hospital General Universitario Alicante, Alicante, Spain \\ Correspondence to: Julio Sesma. C/Pintor Baeza, 12. 03010, Alicante, Spain. Email: jsesmaromero@gmail.com.
}

\begin{abstract}
Video-assisted thoracoscopic surgery (VATS) lung-sparing anatomical resections preserve healthy pulmonary parenchyma but also lead to good resection margins. Oncological outcomes are similar when compared with lobectomy for the treatment of early stage lung adenocarcinoma. VATS technique to perform classical anatomical segmentectomies is well defined and even in highly experienced teams, these procedures can be performed by uniportal VATS. However, the achievement of unusual central anatomical segmentectomies through Uniportal VATS remains a challenge. We describe a feasible and reproducible technique to perform uniportal VATS right lower lateral and posterior (S9-10) anatomical segmentectomy for the treatment of early stage lung cancer.
\end{abstract}

Keywords: Thoracoscopy; video-assisted thoracoscopic surgery (VATS); bronchial neoplasms; pulmonary surgical procedure

Received: 18 September 2019; Accepted: 27 September 2019; Published: 10 April 2020.

doi: 10.21037/shc.2019.09.07

View this article at: http://dx.doi.org/10.21037/shc.2019.09.07

\section{Introduction}

Video-assisted thoracoscopic surgery (VATS) anatomical segmentectomies allow to preserve healthy pulmonary parenchyma under minimal invasive conditions but also lead to good resection margin. For its development a deep knowledge of the intrapulmonary bronchovascular anatomy and all its variants is needed (1-3). Literature supports that oncological results in terms of recurrence and overall survival are similar when compared with lobectomy for the treatment of early stage non-small cell lung cancer (4-7). VATS technique to perform classical anatomical segmentectomies (culmen, lingual lobe, basal segments and superior segment of lower lobe) is well defined (1), even in highly experienced teams, these procedures can be performed by uniportal VATS (8). However, the achievement of unusual central anatomical segmentectomies through uniportal VATS remains a challenge. We present the case of a 70-year-old woman who received uniportal VATS right lower lateral and posterior (S9-10) anatomical segmentectomy with total preservation of segments 6 , 7 and 8 (S6-8) for the treatment of early stage leipidic adenocarcinoma.

\section{How to do it}

A 60-year-old woman was diagnosed of a $1.2 \mathrm{~cm}$ leipidic adenocarcinoma located in the right lower lateral and posterior segments (S9-10) (Figure 1) through transthoracic needle biopsy. Due to histology, size and location a uniportal VATS right S9-10 anatomical segmentectomy was performed (Figure 2) with the aim of preserve S6-8 segments, obtain adequate margin of resection and achieve fasten recovery.

Through a $3 \mathrm{~cm}$ incision in the 5 th intercostal space the major fissure was carefully dissected identifying all the arterial branches of the right lower lobe (Figure $3 \mathrm{~A}$ ). Then, the pulmonary ligament was dissected and all the venous branches of the right lower lobe were also clearly identified (Figure 3B). As S9-10 presents complete 


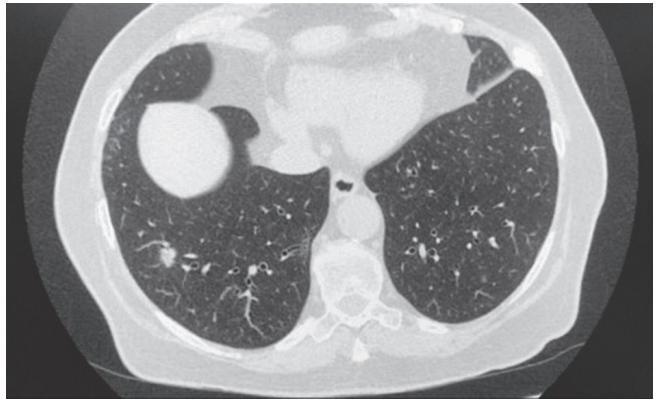

Figure 1 Preoperative CT-scan.

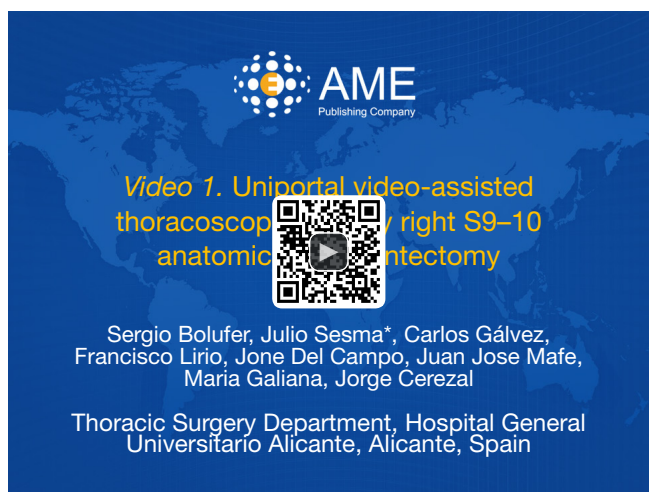

Figure 2 Uniportal video-assisted thoracoscopic surgery right S9-10 anatomical segmentectomy (9).

Available online: http://www.asvide.com/watch/32998

intralobar disposition, in order to control arterial branches for segments S9-10 (A9-10) it was necessary to previously control and pull back the arterial branch of segment 8 (A8), we call this manoeuvre the "loop technique" (Figure 4A). After safely achieve control of A9-10 we transected these branches by using endostapler. Likewise, to control the venous branches of S9-10 (V9-10) it was necessary to perform the loop technique on the venous branch of segment 8 (V8) (Figure 4B). After transect V9-10 the intralobar dissection was progressed (Figure $5 A$ ) allowing to configure the neofissures between S10 and S6, and between S8 and S9 (Figure 5B). This step let's get exposure of the bronchial branches for segments 9 and 10 for the later selective division by using endostaplers (Figure 6). Finally, the specimen was removed and full preservation of S6-8 was obtained. The resection margin was free at $4 \mathrm{~cm}$. Radical lymphadenectomy was completed. Final pathological stage was T1bN0M0. The postoperative period was uneventful, and the patient was discharged home in postoperative day 2
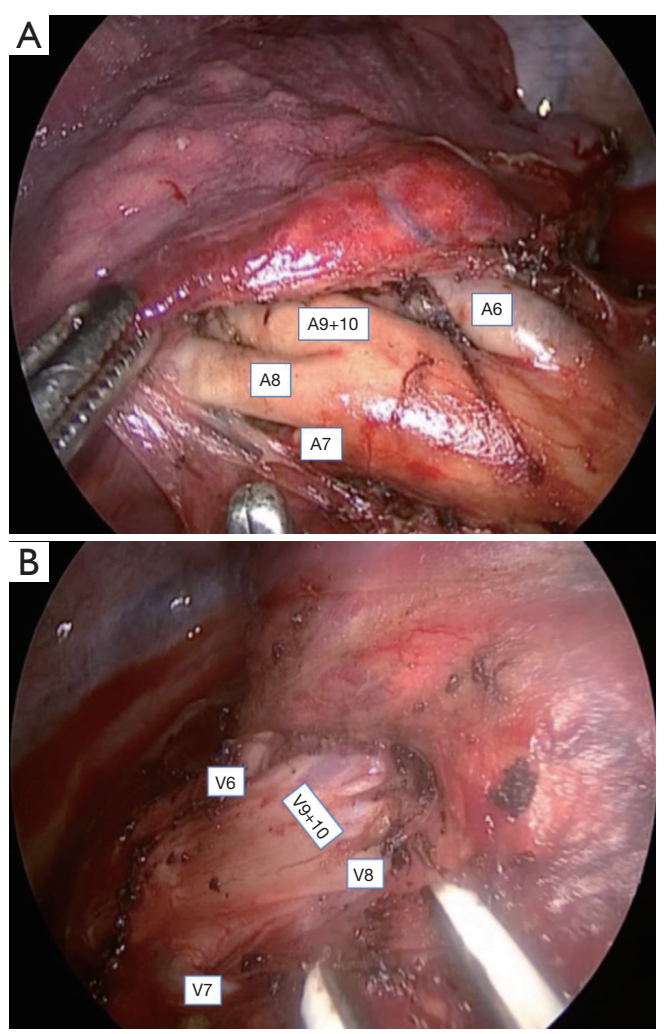

Figure 3 Segmentary identification of arterial branches (A) and venous branches (B) of the right lower lobe.

with satisfactory chest X-ray (Figure 7). After 9 months of follow-up, the patient remains free of disease.

\section{Discussion}

The non-classical anatomical segmentectomies in the lower lobes are infrequent and involve great complexity due to the enormous anatomical variability. Its implementation is strictly limited to particular cases where the lesions are small and clearly located in these segments. In addition, performing an anatomical resection in the most central segments ( $\mathrm{S} 9$ and $\mathrm{S} 10$ ), increases the difficulty since a deeper intrapulmonary dissection is necessary to ensure two appropriate neofissures (between S8 and S9 and between S10 and S6) in order to guarantee a good resection margin. In our case, by doing S9-10 anatomical segmentectomy we achieved the aim of preserving $60 \%$ of the right lower lobe which is very remarkable if comparing with total loss of right lower lobe (lobectomy) or with just one remaining segment (basal segmentectomy). In addition, uniportal 

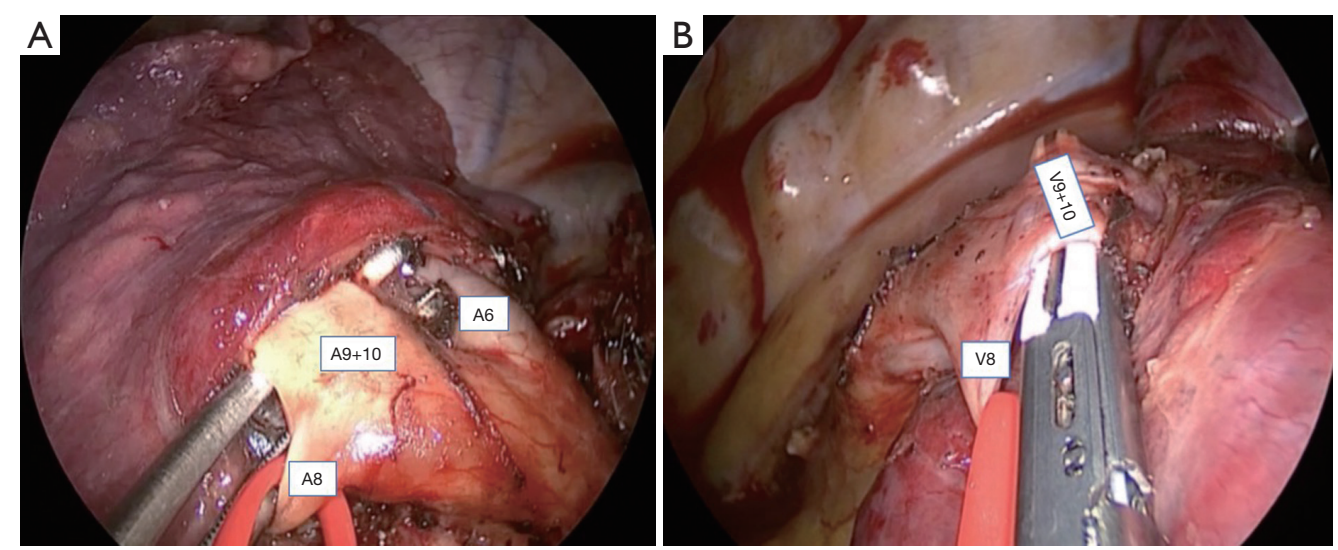

Figure 4 Loop technique for control of A9-10 (A) and V9-10 (B).
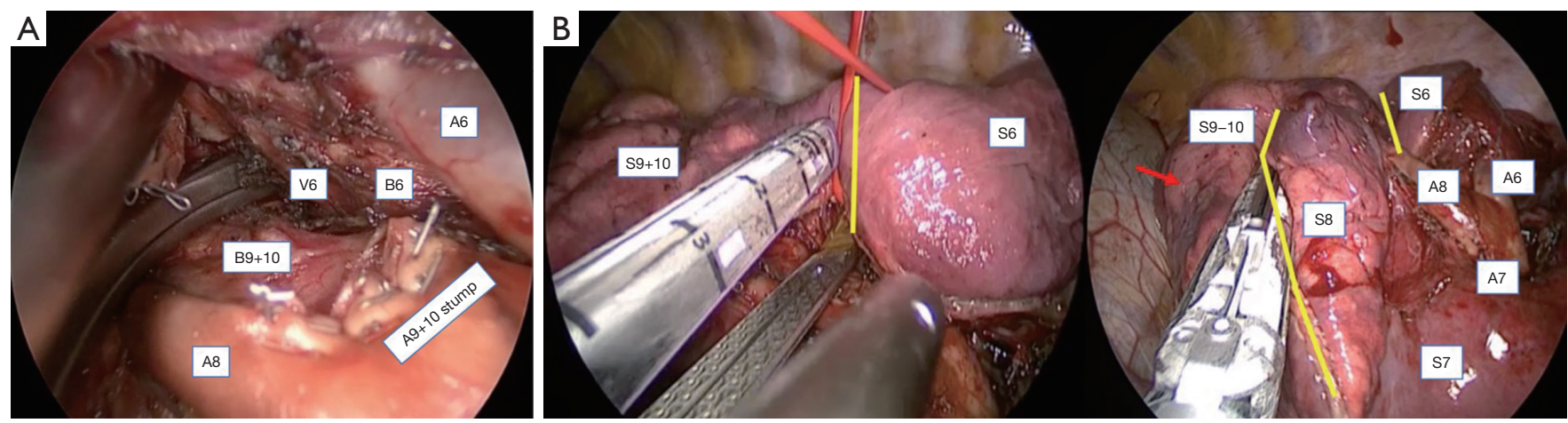

Figure 5 Intralobar dissection (A) in order to allow neofissures configuration (B). Note small localized lesion (red arrow) and the news intersegmentary fissures (yellow lines).
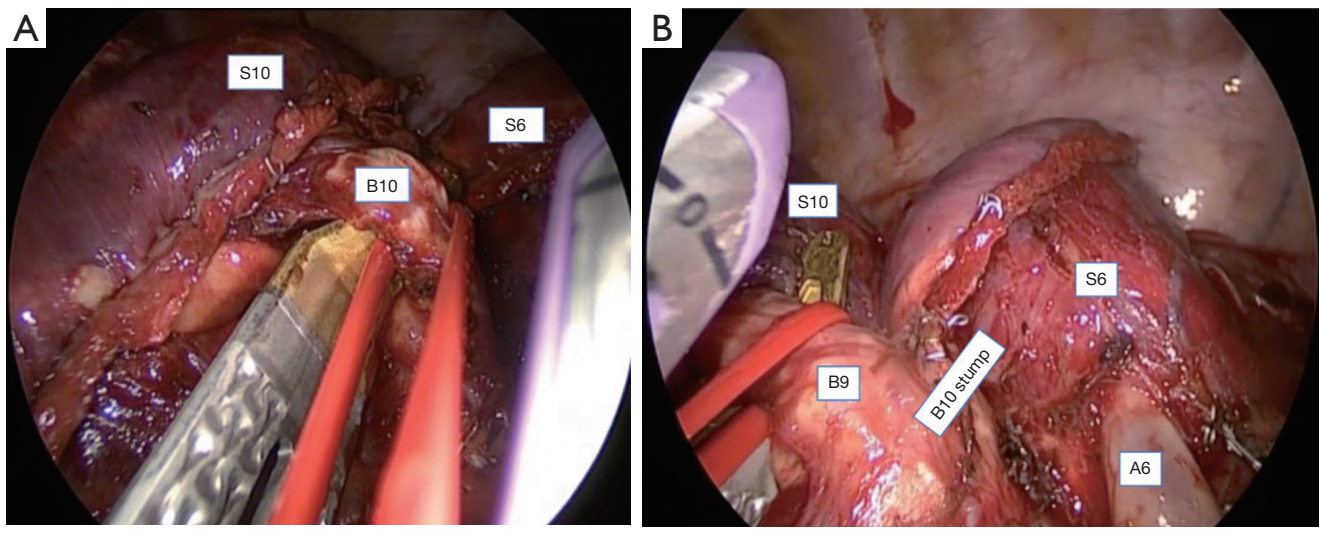

Figure 6 B10 (A) and B9 (B) control and section by endostapler. 


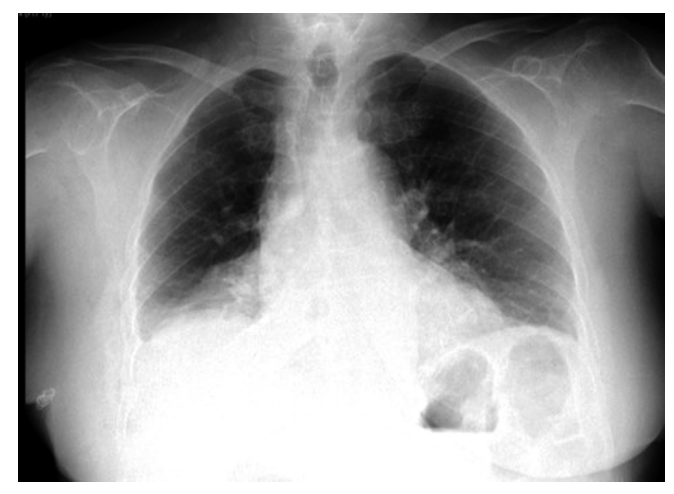

Figure 7 A 48 h postoperative Chest X-ray.

VATS decreased postoperative pain and fastens recovery. Absence of postoperative complications proves this approach is feasible and safe even for unusual central lungsparing anatomical resections as in our case. Despite its high technical complexity, uniportal VATS unusual anatomical segmentectomies are safe and feasible in experienced teams and it is advisable to have previously overcome the uniportal vats learning curve in classical anatomical segmentectomies before performing these procedures.

\section{Acknowledgments}

None.

\section{Footnote}

Conflicts of Interest: The authors have no conflicts of interest to declare.

Ethical Statement: The authors are accountable for all aspects of the work in ensuring that questions related to the accuracy or integrity of any part of the work are appropriately investigated and resolved. Written informed consent was obtained from the patient for publication of this manuscript and any accompanying images.

doi: 10.21037/shc.2019.09.07

Cite this article as: Bolufer S, Sesma J, Gálvez C, Lirio F, Del Campo J, Mafe JJ, Galiana M, Cerezal J. Uniportal videoassisted right S9-10 anatomical segmentectomy: how to do it. Shanghai Chest 2020;4:12.

\section{References}

1. Gossot D, Lutz J, Grogoroiu M, et al. Thoracoscopic anatomic segmentectomies for lung cancer: technical aspects. J Vis Surg 2016;2:171.

2. Nagashima T, Shimizu K, Ohtaki Y, et al. An analysis of variations in the bronchovascular pattern of the right upper lobe using three-dimensional CT angiography and bronchography. Gen Thorac Cardiovasc Surg 2015;63:354-60.

3. Nagashima T, Shimizu K, Ohtaki Y, et al. Analysis of variation in bronchovascular pattern of the right middle and lower lobes of the lung using three-dimensional CT angiography and bronchography. Gen Thorac Cardiovasc Surg 2017;65:343-9.

4. Dziedzic R, Zurek W, Marjanski T, et al. Stage I nonsmall-cell lung cancer: long-term results of lobectomy versus sublobar resection from the Polish National Lung Cancer Registry. Eur J Cardiothorac Surg 2017;52:363-9.

5. Martin-Ucar AE, Nakas A, Pilling JE, et al. A casematched study of anatomical segmentectomy versus lobectomy for stage I lung cancer in high-risk patients. Eur J Cardiothorac Surg 2005;27:675-9.

6. Date H, Andou A, Shimizu N. The value of limited resection for "clinical" stage I peripheral non-small cell lung cancer in poor-risk patients: comparison of limited resection and lobectomy by a computer-assisted matched study. Tumori 1994;80:422-6.

7. Okada M, Yoshikawa K, Hatta T, et al. Is segmentectomy with lymph node assessment an alternative to lobectomy for non-small cell lung cancer of $2 \mathrm{~cm}$ or smaller? Ann Thorac Surg 2001;71:956-60; discussion 961.

8. Galvez C, Sesma J, Bolufer S, et al. Single-incision videoassisted anatomical segmentectomy with handsewn bronchial closure for endobronchial lipoma. Ann Transl Med 2016;4:284.

9. Bolufer S, Sesma J, Gálvez C, et al. Uniportal Videoassisted thoracoscopic surgery right S9-10 anatomical segmentectomy. Asvide 2019;6:313. Available online: http://www.asvide.com/watch/32998 